\title{
Impaired corticomuscular and interhemispheric cortical beta oscillation coupling in amyotrophic lateral sclerosis
}

\author{
Malcolm Proudfoot, DPhil ${ }^{1,2}$ \\ Freek van Ede, $\mathrm{PhD}^{2}$ \\ Andrew Quinn, PhD ${ }^{2}$ \\ Giles L. Colclough, DPhil ${ }^{2}$ \\ Joanne Wuu, ScM ${ }^{3}$ \\ Kevin Talbot, DPhil ${ }^{1}$ \\ Michael Benatar, $\mathrm{PhD}^{3}$ \\ Mark W. Woolrich, $\mathrm{PhD}^{2}$ \\ *Anna C. Nobre, PhD ${ }^{2}$ \\ *Martin R. Turner, PhD ${ }^{1,2}$ \\ ${ }^{1}$ Nuffield Department of Clinical Neurosciences, University of Oxford, Oxford, UK. \\ ${ }^{2}$ Oxford Centre for Human Brain Activity, University of Oxford, Oxford, UK. \\ ${ }^{3}$ Miller School of Medicine, University of Miami, Miami, FL, USA.

$\begin{array}{lll}* \text { Correspondence: } & \text { Prof Martin Turner } & \text { Prof Kia Nobre } \\ & \text { Nuffield Department of } & \text { Oxford Centre for } \\ & \text { Clinical Neurosciences } & \text { Human Brain Activity } \\ \text { John Radcliffe Hospital } & \text { Warneford Hospital } \\ & \text { Oxford OX3 9DU } & \text { Oxford OX3 7JX } \\ & \text { Tel: +44 1865 223380 } & \text { Tel: +44 1865 283800 } \\ & \text { martin.turner@ndcn.ox.ac.uk kia.nobre@ohba.ox.ac.uk }\end{array}$

Word counts: Abstract 200; Body 4053;

Figures 6; Tables 1

Characters (w spaces): Title 103

Abbreviations: Amyotrophic Lateral Sclerosis ALS, Asymptomatic Gene Carriers AGC, Corticomuscular Coherence CMC, Maximum Voluntary Contraction MVC 


\section{Abstract}

\section{Objectives}

The neural activity of the primary motor cortex is variably synchronised with contralateral peripheral electromyographic signals, which is thought to facilitate long-range communication through the motor system. Such corticomuscular coherence (CMC) is typically observed in the beta-band $(15-30 \mathrm{~Hz})$ range during steady force production. We aimed to measure pathological alteration to CMC resulting from ALS.

\section{Methods}

CMC was appraised during a forearm grip task in 17 ALS patients contrasted against agematched healthy controls. An exploratory comparison with a group of asymptomatic ALS gene carriers and neuropathy disease mimics was also undertaken. Neural signals were acquired by whole-head magnetoencephalography and localised via structural MRI to the motor cortices.

\section{Results}

During light voluntary muscular contraction, beta-band CMC was significantly reduced in ALS patients compared to healthy controls. Propagation of motoric beta rhythms across the cortical hemispheres was also shown to be impaired in ALS patients. CMC was preserved in the asymptomatic gene carrier and did not distinguish ALS patients from neuropathy mimics.

\section{Conclusion}

Functional connectivity metrics reveal an ALS-related decrease in both corticomuscular and interhemispheric communication during bilateral grip force production.

\section{Significance}

MEG-derived beta oscillation coupling may be a potential biomarker of motor system dysfunction in ALS, against which to measure future therapeutic efficacy.

Keywords: ALS, MEG, biomarker, coherence

\section{Highlights:}

- Cortical motor output was measured in terms of neural oscillations using magnetoencephalography.

- Patients with ALS demonstrate impaired corticomuscular coherence during grip force production.

- Interhemispheric functional connectivity via beta-band oscillations is compromised by ALS. 


\section{Introduction}

Amyotrophic lateral sclerosis (ALS) is a neurodegenerative disorder of the

corticomotoneuronal system characterised by progressive loss of upper and lower motor neurons in variable proportion (Kiernan et al., 2011). Progress in developing effective therapy for what is typically a severely life-shortening disease is hindered by a lack of objective measures of disease against which to rapidly assess the potential impact of novel treatments (Turner and Benatar, 2015). Magnetoencephalography (MEG) can describe the cortical landscape of electrical rhythms (Proudfoot et al., 2014); alterations in beta-band activity have shed new light on ALS pathophysiology (Proudfoot et al., 2017).

Corticomuscular coherence (CMC) describes a physiological phenomenon by which neural oscillations generated by the motor cortex correlate temporally with electromyographic activity in the contralateral peripheral musculature (Conway et al., 1995), requiring intact upper motor neuron (UMN) pathways (Farmer et al., 1993; Fisher et al., 2012). Diverse cerebral pathologies are reported to affect CMC. Stroke survivors manifest a more distributed range of cortical locations for peak CMC than healthy controls, in keeping with plastic reorganisation of sensorimotor functionality (Farmer et al., 1993; Rossiter et al., 2012). Motor deficits secondary to acute stroke are accompanied by a unilateral reduction in CMC (Nielsen et al., 2008), which then normalises with good functional recovery (von Carlowitz-Ghori et al., 2014). In Parkinson's disease, pathological beta oscillations in the basal ganglia (reviewed previously (Little and Brown, 2014)) are an established therapeutic target for deep-brain stimulation. While CMC appears preserved early in the Parkinson's disease course (Pollok et al., 2012), subsequent symptomatic relief with either L-Dopa 
(Mckeown et al., 2006; Salenius et al., 2002) or DBS (Airaksinen et al., 2015) is accompanied by $\mathrm{CMC}$ modulation. A previous coherence study investigated the impact of two extremes of the ALS clinical spectrum, namely the 'pure' UMN disorder primary lateral sclerosis (PLS) and the lower motor neuron (LMN) condition termed progressive muscular atrophy (PMA), on the functional integrity of cortical drive to the first dorsal interosseous muscle (Fisher et al., 2012). Beta-band intermuscular coherence (a peripheral marker of corticospinal output) was markedly reduced in the PLS group but relatively preserved in PMA, thereby suggesting beta-band coherence to be a promising marker of UMN integrity.

We harnessed the unique sensitivity of MEG to investigate neural coupling in a group of ALS patients, functionally appraising the systemic propagation of beta-band oscillations from the motor cortices. Extending the standard analysis of $\mathrm{CMC}$, we also considered cortico-cortical coherence (focusing on coupling between left and right primary motor cortices), making use of state-of-the-art orthogonalisation approaches that limit confounding spatial leakage as neural signals are mapped into brain space (Colclough et al., 2016). An exploratory analysis was undertaken in a group of healthy individuals at genetically high-risk for future development of ALS to look for pre-symptomatic changes, and a group of motor neuropathy 'ALS mimics' to consider diagnostic specificity. 


\section{Methods}

\subsection{Participants}

ALS patients, and a group with motor-predominant neuropathies, were recruited from the tertiary referral Oxford MND Care and Research Centre. Asymptomatic carriers of ALS-linked genetic mutations (AGCs) were recruited through contact with the Oxford centre, or prior enrolment in the Pre-fALS study based in Miami, USA (Benatar and Wuu, 2012). Physical and brief cognitive assessments were undertaken on the day of MEG, the latter using the Edinburgh Cognitive \& Behavioural ALS Screen (ECAS) (Abrahams et al., 2013). A summary measure of the burden of pathological UMN clinical signs was recorded (Menke et al., 2014). All participants provided written informed consent. The study received prior approval from the National Research Ethics Service South Central Berkshire Committee (14/SC/0083). Details of participants included are presented in Table 1.

\subsection{MEG acquisition}

MEG data were acquired on an Elekta Neuromag 306 channel scanner at the Oxford Centre for Human Brain Activity (OHBA). The participant was seated comfortably in the scanner after a period of task familiarisation. Immediately prior to acquisition a Polhemus 3D tracking system recorded 4 fixed coil positions relative to nasion and preauricular fiducial landmarks, alongside distributed points covering the scalp and face surface (Fig 1A). Coils were intermittently energised to obtain a continuous record of head position with the MEG helmet. Blinks and saccades were monitored continuously using a combination of surface electro-oculography and infra-red eyetracker. ECG was monitored at the wrists. Surface EMG electrodes in a bipolar configuration were positioned $4 \mathrm{~cm}$ apart over flexor digitorum superficialis with a reference electrode on each lateral epicondyle (Fig 1A). 
Participants underwent a structural MRI for co-registration purposes, typically on the same day as MEG, on a Siemens Trio 3T (three-dimensional whole-brain T1-weighted using a magnetisation-prepared rapid gradient echo (MPRAGE) sequence, TR/TE= 2040ms $/ 4.7 \mathrm{ms,}$ flip angle $=8^{\circ}, 1 \mathrm{~mm}$ isotropic resolution, 6 minute acquisition time).

\subsection{Experimental setup}

A visually cued task (Fig 1B) was designed to appraise motor cortical function during brief action preparation. Each trial of the task included a period of either 1 or 2 seconds during which the participant was required to maintain a light grip with both hands, approximating to $20 \%$ of their individually ascertained maximum voluntary contraction (MVC). Our analysis was focused on these preparatory epochs as such tonic contraction is typically associated with the highest CMC (Baker et al., 1997). Grip strength was recorded via a fibre-optic auxotonic-force response device (resistance increasing linearly with displacement) optimised for use in a scanning environment (Current Designs, USA). Live visual feedback, before each trial commenced, guided the participant to maintain grip in both hands at the $20 \%$ MVC level. The trial was aborted with an explanatory on-screen message if grip in either hand fell below $10 \%$ MVC during a trial or if a premature response (defined for this purpose as $60 \% \mathrm{MVC}$ ) was detected prior to the onset of the Go target.

\subsection{Preprocessing}

Raw MEG data were converted to SPM8 format and inspected to identify bad channels prior to processing with Elekta Maxfilter v2.2 (-ST extension, thus creating a set of virtual channels after both signal space separation and continuous head movement compensation). Post-Maxfilter, the filtered data were converted to $\underline{\text { SPM8 }}$, downsampled to $250 \mathrm{~Hz}$. Data 
were then cleaned using a semi-automated SPM8 script as follows. Data was initially highpass filtered at $0.3 \mathrm{~Hz}$. The ICA components corresponding to physiological artefact generated by blink and cardiac cycle were identified and removed from the data. Coregistration was then performed using a version of the SPM8 coregistration adapted to include the registration of headshape points on the bridge of the nose. Coregistration fit was checked for each individual, and if necessary errant headshape points were manually removed prior to repeating the coregistration step. Data were then source-transformed using a linearly constrained minimum variance beamformer, which combines information over both magnetometers and gradiometers and uses principal component analysis (PCA) to regularize the data covariance matrix estimation and account for the reduction in dimensionality caused by Maxfilter, with a single-shell forward model into MNI space at a 3D gridstep of $6 \mathrm{~mm}$ (Woolrich et al., 2011). Source-space variance maps were created in nifti format and inspected for each individual using the FSL tool FSLview (Jenkinson et al., 2012). Three of 42 original participants (one HC, one mimic and one AGC) could not tolerate MRI due to claustrophobia, their data were removed from the MEG analysis. No ALS participants had severe respiratory compromise to preclude MRI. Within each individual, trials were excluded on the basis of incorrect behaviour or after falling beyond 'outlier' detection thresholds in the epoched MEG data. Such noise contaminated trials were detected using a robust bisquare linear regression to fit for the mean standard deviation in the MEG data over trials. Any trials that were estimated as needing to be down-weighted by more than $99 \%$ points during this robust regression were classed as outliers. 
Behavioural analysis was completed via a custom-written semi-automated approach to enable reliable and complete appraisal of behavioural performance in a patient cohort with variable grip strength. Incorrect trials were discarded from the MEG analysis.

\subsection{Corticomuscular communication}

The task structure was designed to maximise signal to noise ratio in $\mathrm{CMC}$ calculation. Only the period of auxotonic forearm contraction during response preparation (1.1s in short trials, $2.1 \mathrm{~s}$ in long trials) was selected, since maintenance of a tonic force reliably induces high levels of cortical beta. EMG data were superficially preprocessed using a highpass filter of $1 \mathrm{~Hz}$ and then rectified (Dakin et al., 2014)). Corticomuscular communication, i.e. a measure of statistical dependency between the MEG signal in cortex and EMG signal in muscle, was calculated using two complementary methods:

Conventional phase-coherence (i.e. corticomuscular coherence or $\mathrm{CMC}$ ).

CMC (as implemented in FieldTrip (Oostenveld et al., 2011)) was calculated between Fourier transformed EMG and MEG (all voxels within an 'M1' parcel defined by functional structure derived from the Human Connectome Project (Colclough et al., 2015; Van Essen et al., 2013)) using discrete prolate spheroidal sequence tapers (Cox et al., 1996) with a frequency smoothing kernel of $5 \mathrm{~Hz}$ across $0.25 \mathrm{~Hz}$ steps from 1 to $40 \mathrm{~Hz}$. The time-frequency transformation was performed twice, initially keeping time resolution and subsequently collapsing across time to reduce within subject variability (as CMC was stable across the preparatory time period). The latter methodology also enabled anatomical source localisation of CMC on a per-voxel basis. 


\section{Amplitude envelope correlation.}

In this approach, Hilbert-transformed data was used to assess amplitude envelope correlations between M1 and contralateral EMG. Amplitude envelope correlation provides a common and robust connectivity metric often used in electrophysiological neuroimaging (Bruns et al., 2000; Hipp et al., 2012), and is equally applicable to the investigation of cortico-spinal coupling (van Ede and Maris, 2013). Amplitude envelopes were estimated using the Hilbert Transform and were obtained from both the parcellated data and the EMG in $1 \mathrm{~Hz}$ steps from 3 to $40 \mathrm{~Hz}$. Amplitude envelope correlation was then calculated as a Pearson correlation coefficient between the time courses. The output from each method was averaged across the number of voxels ( 130 at $6 \mathrm{~mm}$ gridstep) that made up the cortical M1 parcel.

\subsection{Cortico-cortical communication}

The second analysis approach concerned the estimation of cortico-cortical communication during an active muscular contraction. Of a priori interest was the strength (analogous to functional connectivity (Friston, 2011)) with which the two motor cortices (designated as seed regions) communicated with the remaining brain (Nicolo et al., 2015) This method corresponds closely to the Hilbert amplitude envelope correlation described above and selectively took account of the same specific preparatory time period in the task structure. Importantly however, neural time-series from each of 39 cortical parcels were mutually orthogonalised (Colclough et al., 2015) prior to the first PCA component being extracted; this reduces the spatial leakage of neural sources due to uncertainty inherent to the mapping of activity from MEG sensors into brain space. Data were concatenated across sessions, and then Hilbert transformed 4 to $45 \mathrm{~Hz}$ in $0.5 \mathrm{~Hz}$ steps. Communication between 
cortical parcels was assessed after source-leakage correction to reveal a spatial structure emphasising the functional relevance of this connectivity metric, then group inference was selectively focused on coupling between left and right sensori-motor parcels $(n=5)$.

Statistical inferences were performed using a cluster-based permutation approach (Maris and Oostenveld, 2007) as implemented in FieldTrip. This approach is well suited to highdimensional data, as it evaluates clusters of neighbouring samples under a single permutation distribution, to effectively circumvent multiple comparisons. 5000 permutations of group labels were performed, using a clustering threshold of a univariate comparison at an alpha level of 0.05 .

\section{Results}

\subsection{Behavioural}

The average total number of trials successfully completed by each participant is shown by group in Fig 1C. Limiting factors restricting the total number of trials acquired included fatigue, time constraints and (in the case of one AGC) claustrophobia. ALS participants completed slightly fewer trials than HCs $(p=0.094)$. Differences in median response time (RT, correct trials only) were not significant (one-way ANOVA, $p=0.63$ ).

\subsection{Corticomuscular communication}

Source-level beta $\mathrm{CMC}$ with the forearm muscles (Fig 2) revealed that $\mathrm{CMC}$ was consistently strongest within the contralateral precentral gyrus (M1), yet this appeared substantially attenuated in ALS patients. CMC was subsequently appraised between only M1 and the contralateral forearm, and in the preparatory (light grip) period did not show strong 
dependence on either the subsequent response laterality or expected timing of target appearance (results not shown). Comparisons across groups revealed striking differences in overall CMC strength; being markedly reduced in ALS (Fig 3). Group difference contrasts were therefore further appraised after collapsing across time within the auxotonic grip preparatory period.

Comparing ALS participants against HCs revealed a loss of frequency-specific CMC expression. CMC showed a clear bandlimited peak around the classical beta band in $\mathrm{HC}$, but was reduced in ALS, with a significant cluster between 20 to $28 \mathrm{~Hz}(p=0.021$, Fig $4 A$ ). CMC was preserved within the group of AGCs and disrupted albeit not significantly diminished with the mimic group (Fig 4B).

Frequency-resolved corticomuscular amplitude envelope correlation, an alternative corticomuscular coupling metric, confirmed the loss of beta-frequency specific communication in the ALS group, significant between 17 to $24 \mathrm{~Hz}$ ( $p=0.011$, Fig $4 \mathrm{C}$ ). The remaining group differences were directionally similar to the conventional coherence metric of $\mathrm{CMC}$, although non-significant augmentation of contralateral corticomuscular amplitude envelope correlation was observed in the AGC group (Fig 4D).

Both measures of contralateral corticomuscular communication (individual measures averaged within the frequency range of the above described significant group differences) were found to be non-normally distributed by Shapiro-Wilk test $(p<0.01)$. Kendall's Tau was therefore chosen as a more robust indicator of clinical correlations. Across all participants there was no significant correlation between corticomuscular communication (whether 
calculated conventionally as CMC or via Hilbert amplitude envelope) and measures of peripheral grip strength (per the individual's target grip value), mean or SD of the surface EMG, and mean or SD of the gripper output. CMC was not therefore simply related to total muscle activity.

No significant linear correlations were found between clinical measures and either CMC or amplitude envelope correlation. The extent to which $\mathrm{CMC}$ was affected did not statistically depend on the clinical burden of UMN signs.

\subsection{Cortico-cortical communication}

Motor cortex amplitude envelope timecourses showed highest functional connectivity (FC) with anatomically neighbouring regions and with corresponding sensorimotor regions in the opposite hemisphere. A frequency structure was also noted, with amplitude envelope correlation highest in the beta range, in keeping with the elevated beta power induced by the light grip. Group differences were suggested on inspection of amplitude envelope correlation between motor seeds and all remaining parcels. FC appeared to be decreased in ALS patients and increased in AGCs (Fig 5A).

Statistical group comparisons were limited to the cross-hemispheric communication between sensorimotor regions. The frequency-dependent structure to FC, maximal in beta, was again confirmed. Permutation and clustering across frequencies detected lower FC in ALS patients compared with HCs ( $p=0.021$, Fig 5 B) but not significantly lower than disease mimics. 
AGCs appeared to have a slightly lower peak frequency of FC between sensorimotor regions, with a similar absolute level of amplitude envelope correlation, and no significant group differences by permutation testing.

In consideration of the possible confounding factor of group differences in cortical beta power, a summary value was generated per participant from both motor cortices during the same motor preparation time epoch. No significant difference in beta power was detected between ALS patients and HCs (Fig 6A), nonetheless cortical beta power was then regressed out of the above data on a per participant basis. After this correction, summary values (averaged across the beta-band frequency) continued to demonstrate significant group differences between ALS and HC (unpaired t-test with 24 degrees of freedom) in both CMC $(p=0.032)$ and amplitude envelope correlation $(p=0.014)$, and cortico-cortical communication $(p=0.033)$. Uncorrected summary group differences in beta-averaged values are represented in Fig 6B to $\mathbf{D}$.

\section{Discussion}

This study demonstrated a functional alteration of cortical motor output in ALS, extending recent MEG-based delineation of altered cortical beta oscillations during movement (Proudfoot et al., 2017). Beta-band CMC was diminished and beta-band signalling between the motor cortices and other cortical regions also appeared altered by ALS. Specifically, during an auxotonic light grip, interhemispheric beta amplitude correlation was significantly diminished relative to healthy controls (with a directionally similar tendency relative to disease mimics). 
A small and heterogenous group of asymptomatic gene carriers did not appear to share abnormal CMC values, and, to an extent, also showed directionally divergent effects on cortico-cortical amplitude correlation. No significant differences were detected between groups in M1 beta power, when assessed during the same task period as CMC and FC. Attenuated corticomuscular and interhemispheric coupling in ALS are not therefore solely attributable to reduced beta power, importantly substantiating dissociation between cortical beta power and beta $\mathrm{CMC}$, previously investigated via pharmacological manipulation in HCs (Baker and Baker, 2003; Riddle et al., 2004).

\subsection{The neurophysiological basis of corticomuscular coherence}

While the precise functional role of CMC is not completely delineated (van Wijk et al., 2012), tonic contraction is reliably accompanied by significant CMC, maximal in the beta band (15$30 \mathrm{~Hz}$ ) range (Halliday et al., 1998; Salenius et al., 1997). CMC is furthermore readily modified by evolving task demands (Baker et al., 1999, 1997) beyond the required strength of muscular contraction (Brown et al., 1998). Specifically, the precision and predictability of force parameters affect beta CMC amplitude (Kilner et al., 2000; Omlor et al., 2011), and CMC indexes the quality of both motor performance (Kristeva et al., 2007) and new skill learning (Perez et al., 2006). CMC also varies with cognitive demands, in keeping with broader mechanisms to enhance information salience (Coull and Nobre, 1998; Egner and Hirsch, 2005; Rohenkohl and Nobre, 2011) that include modulation of beta oscillations in the motor cortex (Koelewijn et al., 2008; van Wijk et al., 2009) and peripheral muscles (van Ede and Maris, 2013). Corticospinal synchronisation ultimately calibrates the excitability of target ensembles by adjustment of synaptic gain (van Elswijk et al., 2010; Schoffelen et al., 
2005) and similar phase coupling mechanisms underpin efficient long-range communication throughout distributed cortical networks (Kopell et al., 2014; Voytek and Knight, 2015). The dynamic interface between the wider neuronal oscillation landscape and local spike train generators further supports a diverse array of cognitive functions, rapidly responsive to stimulation yet accountable to context (Fries, 2015, 2005).

\subsection{Cortico-spinal dysfunction in ALS}

The current formal diagnostic criteria for ALS (Brooks et al., 2000) require identification of UMN signs on clinical examination but, for diverse reasons, UMN pathology is not always easy to detect (Huynh et al., 2016; Swash, 2012). ALS biomarker development has included functional markers of corticospinal integrity, most consistently revealing abnormalities using a variety of transcranial magnetic stimulation (TMS) based measures of cortical hyperexcitability (previously reviewed in depth (Vucic et al., 2013)). Investigation with TMS may even demonstrate subclinical involvement of corticospinal pathways (Komissarow et al., 2004), to the extent that it may formally contribute to diagnostic criteria in the future (Menon et al., 2015). However, TMS remains heavily dependent on operator skill, is not tolerated by all patients, and may be unsuccessful (albeit not uninformative) in certain subgroups of ALS (in particular PLS patients frequently have 'inexcitable' motor cortices (Geevasinga et al., 2015)).

The present results are concordant with diminished intermuscular coherence (IMC) values demonstrated within a group of PLS patients (Fisher et al., 2012) and more recently in a study of ALS (Issa et al., 2017), emphasising therefore that CMC, IMC or even or-bilateral EMG coherence (Boonstra et al., 2009) might serve to quantify UMN dysfunction in ALS. 
While small sample sizes may limit the present study's power to distinguish between ALS and disease mimics on the basis of CMC, it is pertinent that abnormally low beta IMC was also demonstrated in a group of seven patients with multifocal motor neuropathy (MMN) (Jaiser, 2014). Diminished CMC in MMN might therefore be explained by either abnormal (but necessarily subclinical) sensory dysfunction (Corse et al., 1996; Delmont et al., 2009) or perhaps an unrecognised influence of MMN on the corticospinal tract itself, in keeping with occasional 'soft' UMN clinical signs (Cats et al., 2010) and prolonged CMCTs in patients with anti-ganglioside antibodies (Oshima et al., 2002). The potential influence of LMN pathology on $\mathrm{CMC}$ integrity is worthy of future consideration given the expectation that $\mathrm{MMN}$ is a purely peripheral disorder, typically with normal CMCT (Molinuevo et al., 1999). Regarding ALS, two recent studies have examined unitary spinal cord function contextualised by afferent stimulation. Exploration of motor responses to the H-reflex (Simon et al., 2015) and during peripheral stimulation (Sangari et al., 2016) implicates spinal hyper-excitability, even in clinically unaffected regions. In effect, this may compensate for altered peripheral or cortico-spinal inputs, further complicating the distinction between UMN and LMN pathophysiology.

\subsection{Activity-dependent functional connectivity in ALS}

Considering the absence of correlation with clinical measures (including an 'UMN reflex sum score' (Menke et al., 2014)), rather than simply reflecting corticospinal dysfunction, reduced beta $\mathrm{CMC}$ might be a manifestation of attempted compensation for motor system degeneration. Periods of elevated beta synchrony have been associated with prolonged reaction time latencies (Gilbertson et al., 2005; Matsuya et al., 2013) and beta CMC reliably dissipates with movement. Reduced CMC might therefore result from ALS patients' 
disproportional need to mentally prepare for the upcoming movement, ostensibly in keeping with subjectively greater task difficulty since task practice has been shown to result in higher levels of beta CMC (Larsen et al., 2016). Relative CMC lateralisation in the ALS group might simultaneously have been compromised by dysfunction of interhemispheric communication (Karandreas et al., 2007).

Minor sensory deficits in ALS (Iglesias et al., 2015) might also affect the ascending component of $\mathrm{CMC}$, but sensory abnormalities would fail to account for the finding of impaired interhemispheric FC in ALS, which in itself warrants discussion given the prevailing resting-state findings of increased FC in ALS (Douaud et al., 2011; Menke et al., 2016). A key factor is the substantial difference in physiological state between the motor cortices at rest and during a task, in this instance requiring active maintenance of a prolonged constant grip force. Coupling within the sensorimotor system may depend upon pyramidal neuron activity levels (spike counts increase with movement (Lemon et al., 1986), therefore beta oscillations are not simply an 'idling' rhythm). Higher beta power is likely to be accompanied by higher beta envelope correlations (group differences in other frequency envelope correlations were negligible). The directionally-divergent findings in the small group of AGCs might be a chance finding relating to their younger age-range, but other examples of 'inverted U-shaped' evolution of abnormalities as neurodegeneration progresses are reported and often concluded to be examples of short-lived compensation (Scheller et al., 2014). 


\subsection{Limitations and future considerations}

Group differences in behaviour were reassuringly minimal in this task setting, given that alterations in, for example, movement speed can have an impact on the accompanying neural oscillations and their coupling (Toma et al., 2002). Subtly reduced cortical beta power during light grip in patients with ALS (both absolute and baseline relative levels of beta are important age-dependent co-factors for successful movement (Heinrichs-Graham and Wilson, 2016)), may further contribute to diminished CMC. An additional potential confound to consider is that ALS patients (almost inevitably) were typically weaker than HCs, and the light grip required was a greater proportion of their MVC. However, as previously discussed, neither measure is simply related to force exertion (Stančák et al., 1997) and, in this study, CMC correlated poorly with grip outputs and surface EMG. Additional reassurance is provided by a report of muscle fatigue enhancing beta CMC (Ushiyama et al., 2011).

Cortical sources implicated in the generation of CMC could, because of plastic reorganisation in the face of ALS pathology, be more dispersed across extra-motor regions, thereby leading to an underestimation of beta CMC values (though not supported by Fig 2). Evidence in favour of this hypothesis draws on the task-based functional MRI literature in ALS to include abnormal activations in the ipsilateral motor (Schoenfeld et al., 2005), parietal (Poujois et al., 2013) and superior temporal regions (Stanton et al., 2007).

The small and heterogeneous disease mimic group was in hindsight underpowered to define the diagnostic discriminatory capabilities of $\mathrm{CMC}$. The interpretation is further limited by the wide variation of beta $\mathrm{CMC}$ levels within the $\mathrm{HC}$ group, which hindered the definition of normative range of values. More complex experimental paradigms might be designed to maximise the expression of $\mathrm{CMC}$ within all individuals, for instance inducing motor 
adaptations via a learning task before measuring CMC (Mendez-Balbuena et al., 2012).

Rather than aspiring to a diagnostic role however, $\mathrm{CMC}$ might prove more useful as a marker of disease progression within individuals, although the reliability of this application remains uncertain. A future test-retest longitudinal design could advantageously also define the reliability of $\mathrm{CMC}$ within subjects. By the inclusion of lower limb and bulbar region study, a topographic distribution of $\mathrm{CMC}$ deficits, corresponding to sequential clinical involvement of neighbouring body regions, would complement existing efforts to map in vivo the progressive spread of TDP-43 intracellular abnormalities that define ALS histopathologically (Kassubek et al., 2014). CMC improvements might then further act as a functional readout for target engagement by a disease-modifying drug, although it may also respond favourably in line with symptomatic relief (CMC varied with fatigue levels in MS patients (Tomasevic et al., 2013)).

In conclusion, neural oscillations and their downstream propagation through the motor system are significantly disrupted by ALS. These findings could potentially be developed into an appealingly non-invasive, functional measure that reflects the integrity of complex cortical networks threatened by ALS pathology. 


\section{Acknowledgements}

The authors would like to thank all the participants for their contribution to the study.

MP was supported by a Wellcome Trust Research Training Fellowship (104369/Z/14/Z). FvE was supported by a Marie Skłodowska-Curie Individual Fellowship from the European Commission (ACCESS2WM). GLC was supported by the Research Councils UK Digital Economy Programme (EP/G036861/1). ACN was supported by a Wellcome Trust Senior Investigator Award (104571/ Z/14/Z). MWW and AQ were supported by the Medical Research Council UK MEG Partnership Grant (MR/K005464/1). MRT was supported by a Medical Research Council and Motor Neurone Disease Association Lady Edith Wolfson Senior Clinical Fellowship (MR/K01014X/1). MB and JW were supported by the Muscular Dystrophy Association (4365 and 172123), ALS Association (2015), Kimmelman Estate; ALS Recovery Fund. Further support for the study was received from the National Institute for Health Research Oxford Biomedical Research Centre based at Oxford University Hospitals Trust.

None of the authors have potential conflicts of interest to be disclosed. 


\section{Figure Legends}

\section{Figure 1}

A: Task schematic of visual cues for motor preparation during which bilateral auxotonic grip required prior to unilateral response. B: Experimental setup recording headshape points, capturing surface EMG from the forearm flexors when using the gripper device, and visual display in the MEG scanner. C: Behavioural data demonstrating average total number of trials completed per participants with (D) comparable task performance by all groups.

\section{Figure 2}

Anatomical localisation demonstrates that the peak levels of beta CMC are obtained from neural sources corresponding to the contralateral primary motor cortex. Image thresholded at $\mathrm{CMC}$ of 0.15 .

\section{Figure 3}

Group average time frequency representations demonstrating physiological CMC in the beta $(15-30 \mathrm{~Hz})$ range during a time period of light grip after a visual 'get-ready' signal (displayed at $\mathrm{t}=0$, vertical red dashed line). Responses (strong grip contraction) were typically made around $1.5 \mathrm{~s}$ after the first cue, causing a low frequency evoked response potential in all groups. The frequency range for $\mathrm{CMC}$ is not obviously altered in the study population groups, but the peak CMC intensity appears diminished.

Figure 4

A \& B: CMC between the forearm EMG and contralateral motor cortex, averaged across both sides, during auxotonic force production. The physiological beta peak of CMC is significantly diminished in patients with ALS (A). Asymptomatic gene carriers demonstrate preserved $\mathrm{CMC}$ but disease mimics also fail to reliably generate a beta peak in CMC, thus failing to distinguish them from ALS patients (B). C \& D: Corticomuscular communication appraised via temporal correlation of fluctuation in band-limited power (amplitude envelope, calculated using the Hilbert transformation) as opposed to phase-based coherence measurement. This independent measure confirmed significantly disrupted communication of beta signals in ALS patients relative to HCS (C) but was again normal in gene carriers and impaired in disease mimics (D). Shaded area $=$ standard error of mean.

\section{Figure 5}

A: Neural signal communication between motor cortices and all other cortical parcels appraised via amplitude envelope correlations during grip maintenance. The spatialfrequency structure reveals the highest correlations to be in the beta range with neighbouring parcels and cross-hemispheric homologous regions. B: The cross-hemispheric correlations appear impaired in ALS patients, but preserved in neuropathy mimics and

AGCs.

\section{Figure 6}

Summary values averaged across the beta-band range $(12.5-27.5 \mathrm{~Hz})$. A: No significant difference in motor cortex beta power is noted between ALS and HCs in the motor preparation epoch. By contrast, marked differences are noted between these groups in terms of corticomuscular communication - both coherence (B) and amplitude envelope correlation (C) and also in interhemispheric communication (D). These significant group differences survive correction for cortical beta power. $Y$ axis values are arbitrary, error bars = standard error of mean. 


\section{References}

Abrahams S, Newton J, Niven E, Foley J, Bak TH. Screening for cognition and behaviour changes in ALS. Amyotroph Lateral Scler Frontotemporal Degener 2013:1-6.

doi:10.3109/21678421.2013.805784.

Airaksinen K, Mäkelä JP, Nurminen J, Luoma J, Taulu S, Ahonen A, et al. Cortico-muscular coherence in advanced Parkinson's disease with deep brain stimulation. Clin Neurophysiol 2015;126:748-55. doi:10.1016/j.clinph.2014.07.025.

Baker MR, Baker SN. The effect of diazepam on motor cortical oscillations and corticomuscular coherence studied in man. J Physiol 2003;546:931-42.

doi:10.1113/jphysiol.2002.029553.

Baker SN, Kilner JM, Pinches EM, Lemon RN. The role of synchrony and oscillations in the motor output. Exp Brain Res 1999;128:109-17.

Baker SN, Olivier E, Lemon RN. Coherent oscillations in monkey motor cortex and hand muscle EMG show task-dependent modulation. J Physiol 1997;501:225-41.

doi:10.1111/j.1469-7793.1997.225bo.x.

Benatar M, Wuu J. Presymptomatic studies in ALS: rationale, challenges, and approach. Neurology 2012;79:1732-9. doi:10.1212/WNL.0b013e31826e9b1d.

Boonstra TW, van Wijk BCM, Praamstra P, Daffertshofer A. Corticomuscular and bilateral EMG coherence reflect distinct aspects of neural synchronization. Neurosci Lett 2009;463:17-21. doi:10.1016/j.neulet.2009.07.043.

Brooks BR, Miller RG, Swash M, Munsat TL. El Escorial revisited: Revised criteria for the diagnosis of amyotrophic lateral sclerosis. Amyotroph Lateral Scler Other Mot Neuron Disord 2000;1:293-9. doi:10.1080/146608200300079536.

Brown P, Salenius S, Rothwell JC, Hari R. Cortical correlate of the Piper rhythm in humans. J Neurophysiol 1998;80:2911-7.

Bruns A, Eckhorn R, Jokeit H, Ebner A. Amplitude envelope correlation detects coupling among incoherent brain signals. Neuroreport 2000;11:1509-14. doi:10.1097/00001756200005150-00028.

von Carlowitz-Ghori K, Bayraktaroglu Z, Hohlefeld FU, Losch F, Curio G, Nikulin V V. Corticomuscular coherence in acute and chronic stroke. Clin Neurophysiol 2014;125:118291. doi:10.1016/j.clinph.2013.11.006.

Cats EA, Van Der Pol WL, Piepers S, Franssen H, Jacobs BC, Van Den Berg-Vos RM, et al. Correlates of outcome and response to IVIg in 88 patients with multifocal motor neuropathy. Neurology 2010;75:818-25. doi:10.1212/WNL.0b013e3181f0738e.

Colclough GL, Brookes MJ, Smith SM, Woolrich MW. A symmetric multivariate leakage correction for MEG connectomes. Neuroimage 2015;117:439-48.

doi:10.1016/j.neuroimage.2015.03.071.

Colclough GL, Woolrich MW, Tewarie PK, Brookes MJ, Quinn AJ, Smith SM. How reliable are MEG resting-state connectivity metrics? Neuroimage 2016;138:284-93. 
doi:10.1016/j.neuroimage.2016.05.070.

Conway BA, Halliday DM, Farmer SF, Shahani U, Maas P, Weir Al, et al. Synchronization between motor cortex and spinal motoneuronal pool during the performance of a maintained motor task in man. J Physiol 1995;489 ( Pt 3:917-24.

Corse AM, Chaudhry V, Crawford TO, Cornblath DR, Kuncl RW, Griffin JW. Sensory nerve pathology in multifocal motor neuropathy. Ann Neurol 1996;39:319-25. doi:10.1002/ana.410390308.

Coull JT, Nobre AC. Where and when to pay attention: the neural systems for directing attention to spatial locations and to time intervals as revealed by both PET and fMRI. J Neurosci 1998;18:7426-35. doi:0270-6474/98/187426-10\$05.00/0.

Cox DD, Percival DB, Walden AT. Spectral Analysis for Physical Applications: Multitaper and Conventional Univariate Techniques. Technometrics 1996;38:294. doi:10.2307/1270624.

Dakin CJ, Dalton BH, Luu BL, Blouin J-S. Rectification is required to extract oscillatory envelope modulation from surface electromyographic signals. J Neurophysiol 2014;112:1685-91. doi:10.1152/jn.00296.2014.

Delmont E, Benaïm C, Launay M, Sacconi S, Soriani MH, Desnuelle C. Do patients having a decrease in SNAP amplitude during the course of MMN present with a different condition? J Neurol 2009;256:1876-80. doi:10.1007/s00415-009-5217-0.

Douaud G, Filippini N, Knight S, Talbot K, Turner MR. Integration of structural and functional magnetic resonance imaging in amyotrophic lateral sclerosis. Brain 2011;134:3470-9. doi:10.1093/brain/awr279.

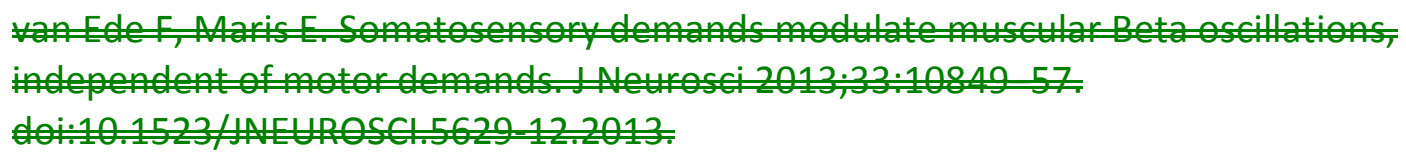

Egner T, Hirsch J. Cognitive control mechanisms resolve conflict through cortical amplification of task-relevant information. Nat Neurosci 2005;8:1784-90. doi:10.1038/nn1594.

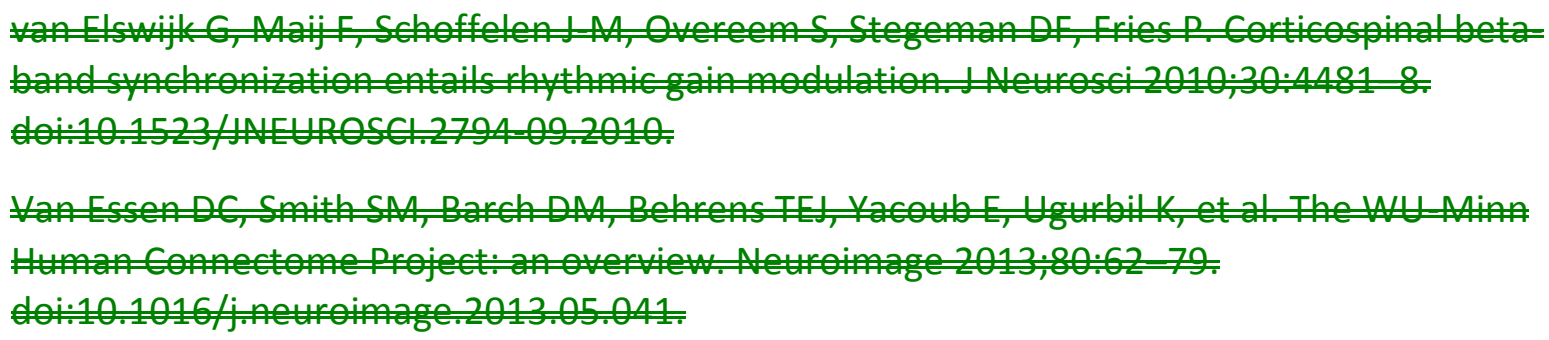

Farmer SF, Swash M, Ingram DA, Stephens JA. Changes in motor unit synchronization following central nervous lesions in man. J Physiol 1993;463:83-105. doi:10.1113/jphysiol.1993.sp019585.

Fisher KM, Zaaimi B, Williams TL, Baker SN, Baker MR. Beta-band intermuscular coherence: a novel biomarker of upper motor neuron dysfunction in motor neuron disease. Brain 2012;135:2849-64. doi:10.1093/brain/aws150.

Fries P. Rhythms for Cognition: Communication through Coherence. Neuron 2015;88:220- 
35. doi:10.1016/j.neuron.2015.09.034.

Fries P. A mechanism for cognitive dynamics: neuronal communication through neuronal coherence. Trends Cogn Sci 2005;9:474-80. doi:10.1016/j.tics.2005.08.011.

Friston KJ. Functional and effective connectivity: a review. Brain Connect 2011;1:13-36. doi:10.1089/brain.2011.0008.

Geevasinga N, Menon P, Sue CM, Kumar KR, Ng K, Yiannikas C, et al. Cortical excitability changes distinguish the motor neuron disease phenotypes from hereditary spastic paraplegia. Eur J Neurol 2015;22:826-e58. doi:10.1111/ene.12669.

Gilbertson T, Lalo E, Doyle L, Di Lazzaro V, Cioni B, Brown P. Existing motor state is favored at the expense of new movement during $13-35 \mathrm{~Hz}$ oscillatory synchrony in the human corticospinal system. J Neurosci 2005;25:7771-9. doi:10.1523/JNEUROSCI.1762-05.2005.

Halliday DM, Conway BA, Farmer SF, Rosenberg JR. Using electroencephalography to study functional coupling between cortical activity and electromyograms during voluntary contractions in humans. Neurosci Lett 1998;241:5-8. doi:10.1016/S0304-3940(97)00964-6.

Heinrichs-Graham E, Wilson TW. Is an absolute level of cortical beta suppression required for proper movement? Magnetoencephalographic evidence from healthy aging.

Neuroimage 2016;134:514-21. doi:10.1016/j.neuroimage.2016.04.032.

Hipp JF, Hawellek DJ, Corbetta M, Siegel M, Engel AK. Large-scale cortical correlation structure of spontaneous oscillatory activity. Nat Neurosci 2012;15:884-90. doi:10.1038/nn.3101.

Huynh W, Simon NG, Grosskreutz J, Turner MR, Vucic S, Kiernan MC. Assessment of the upper motor neuron in amyotrophic lateral sclerosis. Clin Neurophysiol 2016;127:2643-60. doi:10.1016/j.clinph.2016.04.025.

Iglesias C, Sangari S, El Mendili M-M, Benali H, Marchand-Pauvert V, Pradat P-F. Electrophysiological and spinal imaging evidences for sensory dysfunction in amyotrophic lateral sclerosis. BMJ Open 2015;5:e007659. doi:10.1136/bmjopen-2015-007659.

Issa NP, Frank S, Roos RP, Soliven B, Towle VL, Rezania K. Intermuscular coherence in amyotrophic lateral sclerosis: A preliminary assessment. Muscle and Nerve 2017;55:862-8. doi:10.1002/mus.25426.

Jaiser S. Non-invasive electrophysiological assessment of the corticospinal tract in health and disease. Newcastle University, 2014.

Jenkinson M, Beckmann CF, Behrens TEJ, Woolrich MW, Smith SM. FSL. Neuroimage 2012;62:782-90. doi:10.1016/j.neuroimage.2011.09.015.

Karandreas N, Papadopoulou M, Kokotis P, Papapostolou A, Tsivgoulis G, Zambelis T. Impaired interhemispheric inhibition in amyotrophic lateral sclerosis. Amyotroph Lateral Scler 2007;8:112-8. doi:10.1080/17482960601030113.

Kassubek J, Muller H-P, Del Tredici K, Brettschneider J, Pinkhardt EH, Lule D, et al. Diffusion tensor imaging analysis of sequential spreading of disease in amyotrophic lateral sclerosis confirms patterns of TDP-43 pathology. Brain 2014:1-8. doi:10.1093/brain/awu090. 
Kiernan MC, Vucic S, Cheah BC, Turner MR, Eisen A, Hardiman O, et al. Amyotrophic lateral sclerosis. Lancet 2011;377:942-55. doi:10.1016/S0140-6736(10)61156-7.

Kilner JM, Baker SN, Salenius S, Hari R, Lemon RN. Human cortical muscle coherence is directly related to specific motor parameters. J Neurosci 2000;20:8838-45. doi:20/23/8838 [pii].

Koelewijn T, van Schie HT, Bekkering H, Oostenveld R, Jensen O. Motor-cortical beta oscillations are modulated by correctness of observed action. Neuroimage 2008;40:767-75. doi:10.1016/j.neuroimage.2007.12.018.

Komissarow L, Rollnik JD, Bogdanova D, Krampfl K, Khabirov FA, Kossev A, et al. Triple stimulation technique (TST) in amyotrophic lateral sclerosis. Clin Neurophysiol 2004;115:356-60. doi:10.1016/j.clinph.2003.10.003.

Kopell NJ, Gritton HJ, Whittington MA, Kramer MA. Beyond the Connectome: The Dynome. Neuron 2014;83:1319-28. doi:10.1016/j.neuron.2014.08.016.

Kristeva R, Patino L, Omlor W. Beta-range cortical motor spectral power and corticomuscular coherence as a mechanism for effective corticospinal interaction during steady-state motor output. Neuroimage 2007;36:785-92. doi:10.1016/j.neuroimage.2007.03.025.

Larsen LH, Jensen T, Christensen MS, Lundbye-Jensen J, Langberg H, Nielsen JB. Changes in corticospinal drive to spinal motoneurones following tablet-based practice of manual dexterity. Physiol Rep 2016;4:e12684. doi:10.14814/phy2.12684.

Lemon RN, Mantel GW, Muir RB. Corticospinal facilitation of hand muscles during voluntary movement in the conscious monkey. J Physiol 1986;381:497-527. doi:3625543.

Little S, Brown P. The functional role of beta oscillations in Parkinson's disease. Parkinsonism Relat Disord 2014;20 Suppl 1:S44-8. doi:10.1016/S1353-8020(13)70013-0.

Maris E, Oostenveld R. Nonparametric statistical testing of EEG- and MEG-data. J Neurosci Methods 2007;164:177-90. doi:10.1016/j.jneumeth.2007.03.024.

Matsuya R, Ushiyama J, Ushiba J. Prolonged reaction time during episodes of elevated $\beta$ band corticomuscular coupling and associated oscillatory muscle activity. J Appl Physiol 2013;114:896-904. doi:10.1152/japplphysiol.00942.2012.

Mckeown MJ, Palmer SJ, Au W-L, Mccaig RG, Saab R, Abu-Gharbieh R. Cortical muscle coupling in Parkinson's disease (PD) bradykinesia. J Neural Transm 2006;70:31-40.

Mendez-Balbuena I, Huethe F, Schulte-Mönting J, Leonhart R, Manjarrez E, Kristeva R. Corticomuscular coherence reflects interindividual differences in the state of the corticomuscular network during low-level static and dynamic forces. Cereb Cortex 2012;22:628-38. doi:10.1093/cercor/bhr147.

Menke R a L, Körner S, Filippini N, Douaud G, Knight S, Talbot K, et al. Widespread grey matter pathology dominates the longitudinal cerebral MRI and clinical landscape of amyotrophic lateral sclerosis. Brain 2014;137:2546-55. doi:10.1093/brain/awu162.

Menke RAL, Proudfoot M, Wuu J, Andersen PM, Talbot K, Benatar M, et al. Increased functional connectivity common to symptomatic amyotrophic lateral sclerosis and those at 
genetic risk. J Neurol Neurosurg Psychiatry 2016;87:580-8. doi:10.1136/jnnp-2015-311945.

Menon P, Geevasinga N, Yiannikas C, Howells J, Kiernan MC, Vucic S. Sensitivity and specificity of threshold tracking transcranial magnetic stimulation for diagnosis of amyotrophic lateral sclerosis: a prospective study. Lancet Neurol 2015;14:478-84. doi:10.1016/S1474-4422(15)00014-9.

Molinuevo J., Cruz-Martinez A, Graus F, Serra J, Ribalta T, Valls-Solé J. Central Motor Conduction Time in Patients With Multifocal Motor. Muscle Nerve 1999;22:926-32.

Nicolo P, Rizk S, Magnin C, Pietro M Di, Schnider A, Guggisberg AG. Coherent neural oscillations predict future motor and language improvement after stroke. Brain 2015;138:3048-60. doi:10.1093/brain/awv200.

Nielsen JB, Brittain JS, Halliday DM, Marchand-Pauvert V, Mazevet D, Conway BA. Reduction of common motoneuronal drive on the affected side during walking in hemiplegic stroke patients. Clin Neurophysiol 2008;119:2813-8. doi:10.1016/j.clinph.2008.07.283.

Omlor W, Patino L, Mendez-Balbuena I, Schulte-Mönting J, Kristeva R. Corticospinal betarange coherence is highly dependent on the pre-stationary motor state. J Neurosci 2011;31:8037-45. doi:10.1523/JNEUROSCI.4153-10.2011.

Oostenveld R, Fries P, Maris E, Schoffelen JM. FieldTrip: Open source software for advanced analysis of MEG, EEG, and invasive electrophysiological data. Comput Intell Neurosci 2011;2011:1-9. doi:10.1155/2011/156869.

Oshima Y, Mitsui T, Yoshino H, Endo I, Kunishige M, Asano a, et al. Central motor conduction in patients with anti-ganglioside antibody associated neuropathy syndromes and hyperreflexia. J Neurol Neurosurg Psychiatry 2002;73:568-73. doi:10.1136/jnnp.73.5.568.

Perez MA, Lundbye-Jensen J, Nielsen JB. Changes in corticospinal drive to spinal motoneurones following visuo-motor skill learning in humans. J Physiol 2006;573:843-55. doi:10.1113/jphysiol.2006.105361.

Pollok B, Krause V, Martsch W, Wach C, Schnitzler a, Südmeyer M. Motor-cortical oscillations in early stages of Parkinson's disease. J Physiol 2012;590:3203-12. doi:10.1113/jphysiol.2012.231316.

Poujois A, Schneider FC, Faillenot I, Camdessanché J-P, Vandenberghe N, Thomas-Antérion $C$, et al. Brain plasticity in the motor network is correlated with disease progression in amyotrophic lateral sclerosis. Hum Brain Mapp 2013;34:2391-401. doi:10.1002/hbm.22070.

Proudfoot M, Rohenkohl G, Quinn A, Colclough GL, Wuu J, Talbot K, et al. Altered cortical beta-band oscillations reflect motor system degeneration in amyotrophic lateral sclerosis. Hum Brain Mapp 2017;38:237-54. doi:10.1002/hbm.23357.

Proudfoot M, Woolrich MW, Nobre AC, Turner MR. Magnetoencephalography. Pract Neurol 2014;14:336-43. doi:10.1136/practneurol-2013-000768.

Riddle CN, Baker MR, Baker SN. The effect of carbamazepine on human corticomuscular coherence. Neuroimage 2004;22:333-40. doi:10.1016/j.neuroimage.2003.12.040.

Rohenkohl G, Nobre a. C. Alpha Oscillations Related to Anticipatory Attention Follow Temporal Expectations. J Neurosci 2011;31:14076-84. doi:10.1523/JNEUROSCI.3387- 


\subsection{1.}

Rossiter HE, Eaves C, Davis E, Boudrias M-H, Park C-H, Farmer S, et al. Changes in the location of cortico-muscular coherence following stroke. Neurolmage Clin 2012;2:50-5. doi:10.1016/j.nicl.2012.11.002.

Salenius S, Avikainen S, Kaakkola S, Hari R, Brown P. Defective cortical drive to muscle in Parkinson's disease and its improvement with levodopa. Brain 2002;125:491-500. doi:10.1093/brain/awf042.

Salenius S, Portin K, Kajola M, Salmelin R, Hari R. Cortical control of human motoneuron firing during isometric contraction. J Neurophysiol 1997;77:3401-5. doi:10.1016/j.conb.2003.10.008.

Sangari S, Iglesias C, El Mendili MM, Benali H, Pradat PF, Marchand-Pauvert V. Impairment of sensory-motor integration at spinal level in amyotrophic lateral sclerosis. Clin Neurophysiol 2016;127:1968-77. doi:10.1016/j.clinph.2016.01.014.

Scheller E, Minkova L, Leitner M, Klöppel S. Attempted and successful compensation in preclinical and early manifest neurodegeneration - a review of task FMRI studies. Front Psychiatry 2014;5:132. doi:10.3389/fpsyt.2014.00132.

Schoenfeld MA, Tempelmann C, Gaul C, Kühnel GR, Düzel E, Hopf J-M, et al. Functional motor compensation in amyotrophic lateral sclerosis. J Neurol 2005;252:944-52. doi:10.1007/s00415-005-0787-y.

Schoffelen J-M, Oostenveld R, Fries P. Neuronal coherence as a mechanism of effective corticospinal interaction. Science 2005;308:111-3. doi:10.1126/science.1107027.

Simon NG, Lin CSY, Lee M, Howells J, Vucic S, Burke D, et al. Segmental motoneuronal dysfunction is a feature of amyotrophic lateral sclerosis. Clin Neurophysiol 2015;126:82836. doi:10.1016/j.clinph.2014.07.029.

Stančák A, Riml A, Pfurtscheller G. The effects of external load on movement-related changes of the sensorimotor EEG rhythms. Electroencephalogr Clin Neurophysiol 1997;102:495-504. doi:10.1016/S0013-4694(96)96623-0.

Stanton BR, Williams VC, Leigh PN, Williams SCR, Blain CR V, Jarosz JM, et al. Altered cortical activation during a motor task in ALS. Evidence for involvement of central pathways. J Neurol 2007;254:1260-7. doi:10.1007/s00415-006-0513-4.

Swash M. Why are upper motor neuron signs difficult to elicit in amyotrophic lateral sclerosis? J Neurol Neurosurg Psychiatry 2012;83:659-62. doi:10.1136/jnnp-2012-302315.

Toma K, Mima T, Matsuoka T, Gerloff C, Ohnishi T, Koshy B, et al. Movement rate effect on activation and functional coupling of motor cortical areas. J Neurophysiol 2002;88:3377-85. doi:10.1152/jn.00281.2002.

Tomasevic L, Zito G, Pasqualetti P, Filippi M, Landi D, Ghazaryan a, et al. Cortico-muscular coherence as an index of fatigue in multiple sclerosis. Mult Scler 2013;19:334-43. doi:10.1177/1352458512452921.

Turner MR, Benatar M. Ensuring continued progress in biomarkers for amyotrophic lateral sclerosis. Muscle Nerve 2015;51:14-8. doi:10.1002/mus.24470. 
Ushiyama J, Katsu M, Masakado Y, Kimura A, Liu M, Ushiba J, et al. Muscle fatigue-induced enhancement of corticomuscular coherence following sustained submaximal isometric contraction of the tibialis anterior muscle. J Appl Physiol 2011;110:1233-40. doi:10.1152/japplphysiol.01194.2010.-Oscillatory.

Voytek B, Knight RT. Dynamic network communication as a unifying neural basis for cognition, development, aging, and disease. Biol Psychiatry 2015;77:1089-97. doi:10.1016/j.biopsych.2015.04.016.

Vucic S, Ziemann U, Eisen A, Hallett M, Kiernan MC. Transcranial magnetic stimulation and amyotrophic lateral sclerosis: pathophysiological insights. J Neurol Neurosurg Psychiatry 2013;84:1161-70. doi:10.1136/jnnp-2012-304019.

van Ede F, Maris E. Somatosensory demands modulate muscular Beta oscillations, independent of motor demands. J Neurosci 2013;33:10849-57. doi:10.1523/JNEUROSCI.5629-12.2013.

van Elswijk G, Maij F, Schoffelen J-M, Overeem S, Stegeman DF, Fries P. Corticospinal betaband synchronization entails rhythmic gain modulation. J Neurosci 2010;30:4481-8. doi:10.1523/JNEUROSCI.2794-09.2010.

Van Essen DC, Smith SM, Barch DM, Behrens TEJ, Yacoub E, Ugurbil K, et al. The WU-Minn Human Connectome Project: an overview. Neuroimage 2013;80:62-79. doi:10.1016/j.neuroimage.2013.05.041.

van Wijk BCM, Beek PJ, Daffertshofer A. Neural synchrony within the motor system: what have we learned so far? Front Hum Neurosci 2012;6:252. doi:10.3389/fnhum.2012.00252.

van Wijk BCM, Daffertshofer a, Roach N, Praamstra P. A role of beta oscillatory synchrony in biasing response competition? Cereb Cortex 2009;19:1294-302. doi:10.1093/cercor/bhn174.

Woolrich M, Hunt L, Groves A, Barnes G. MEG beamforming using Bayesian PCA for adaptive data covariance matrix regularization. Neuroimage 2011;57:1466-79.

doi:10.1016/j.neuroimage.2011.04.041. 

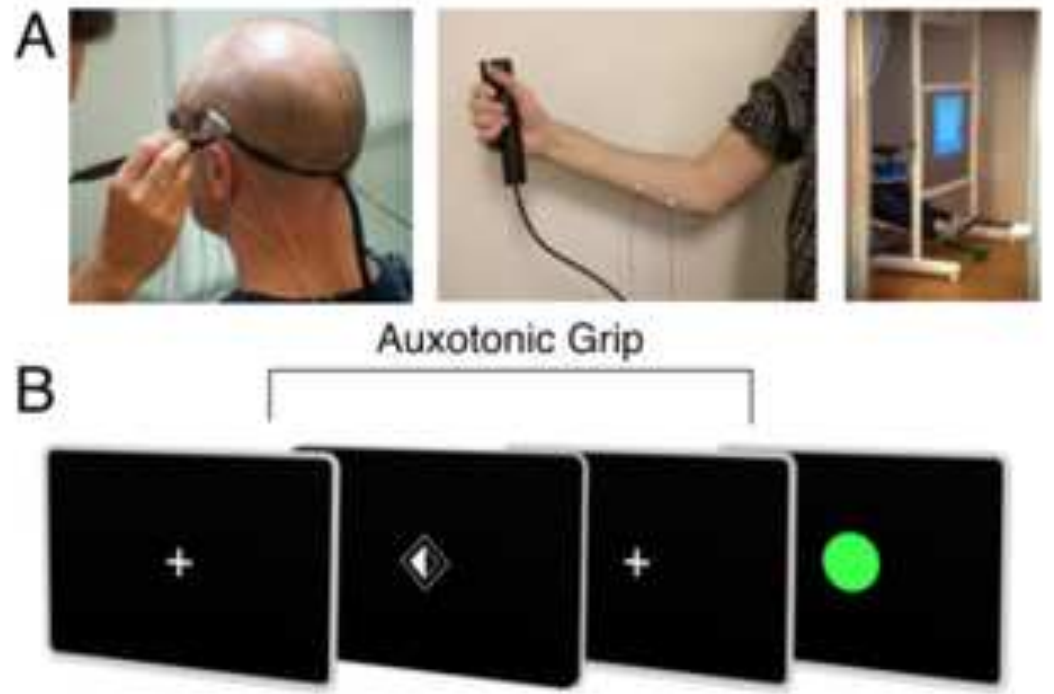


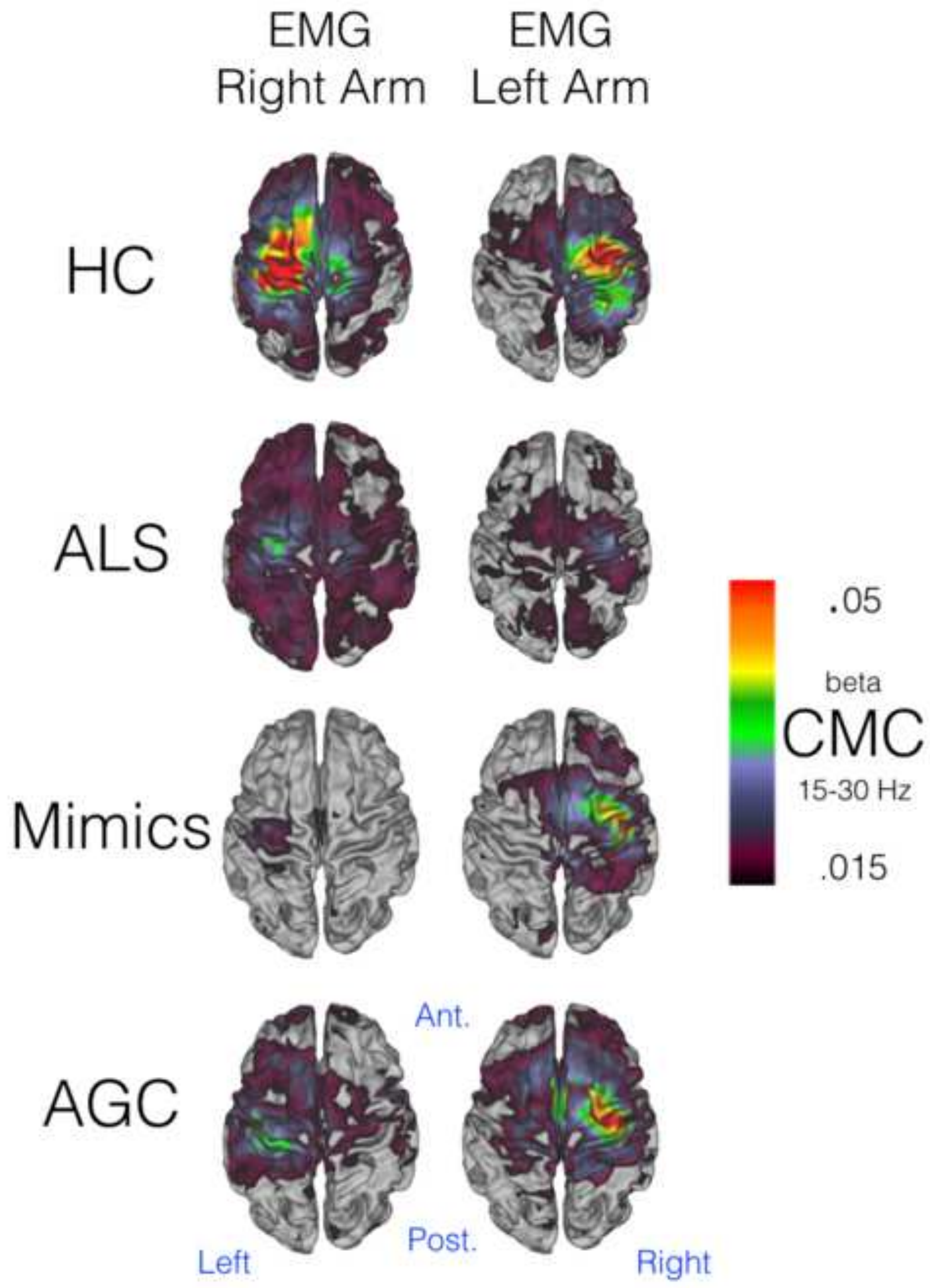




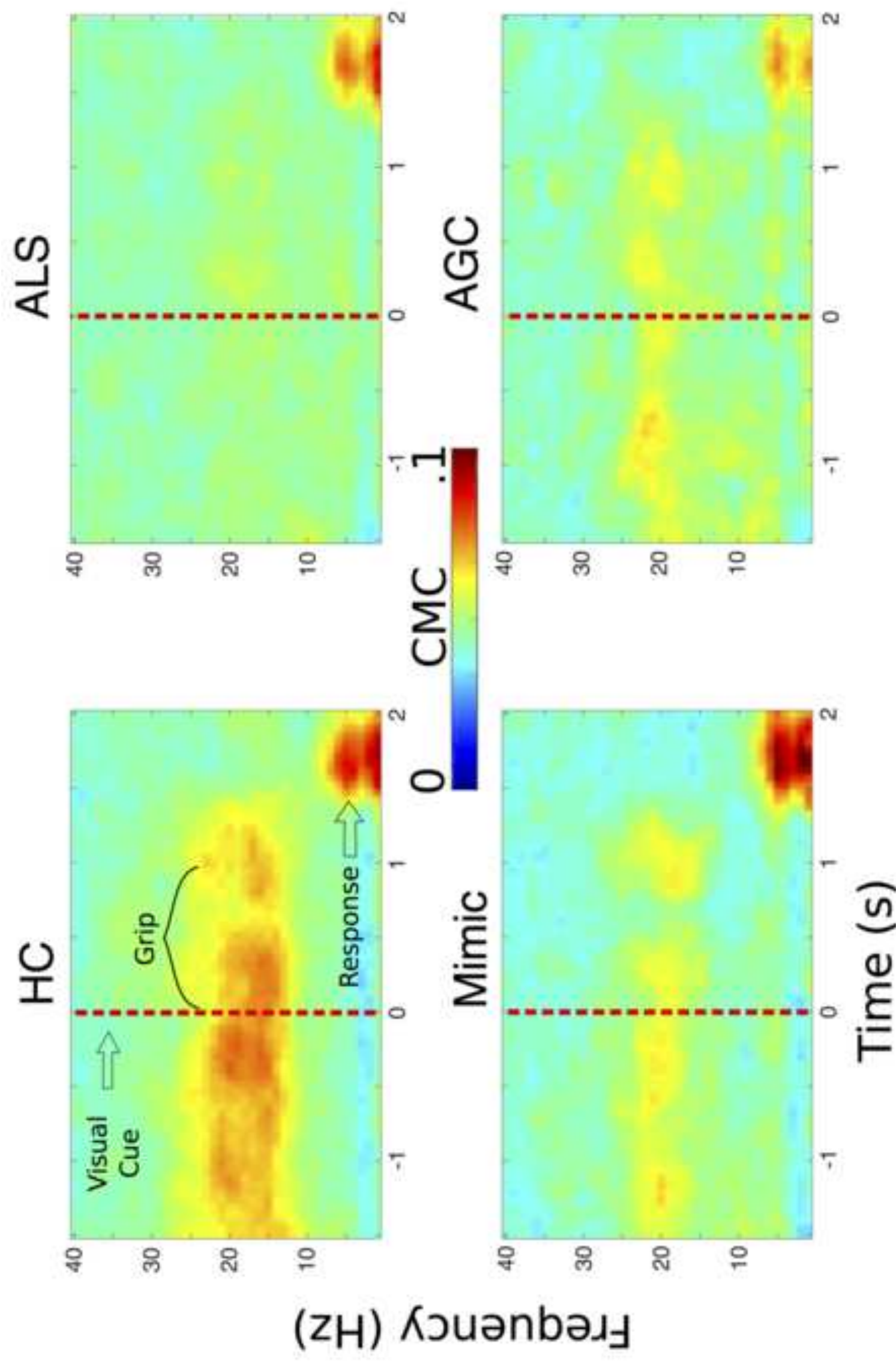



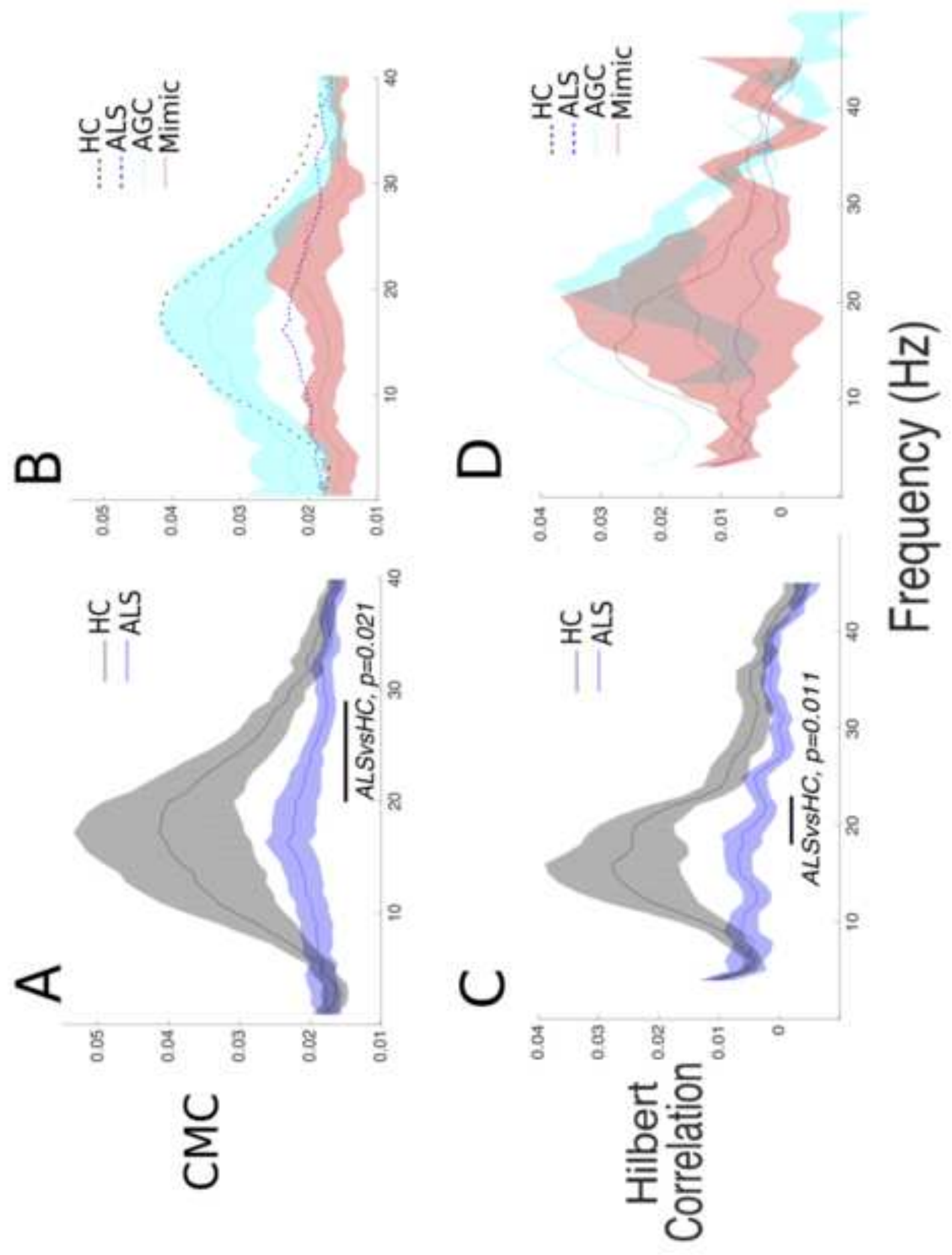

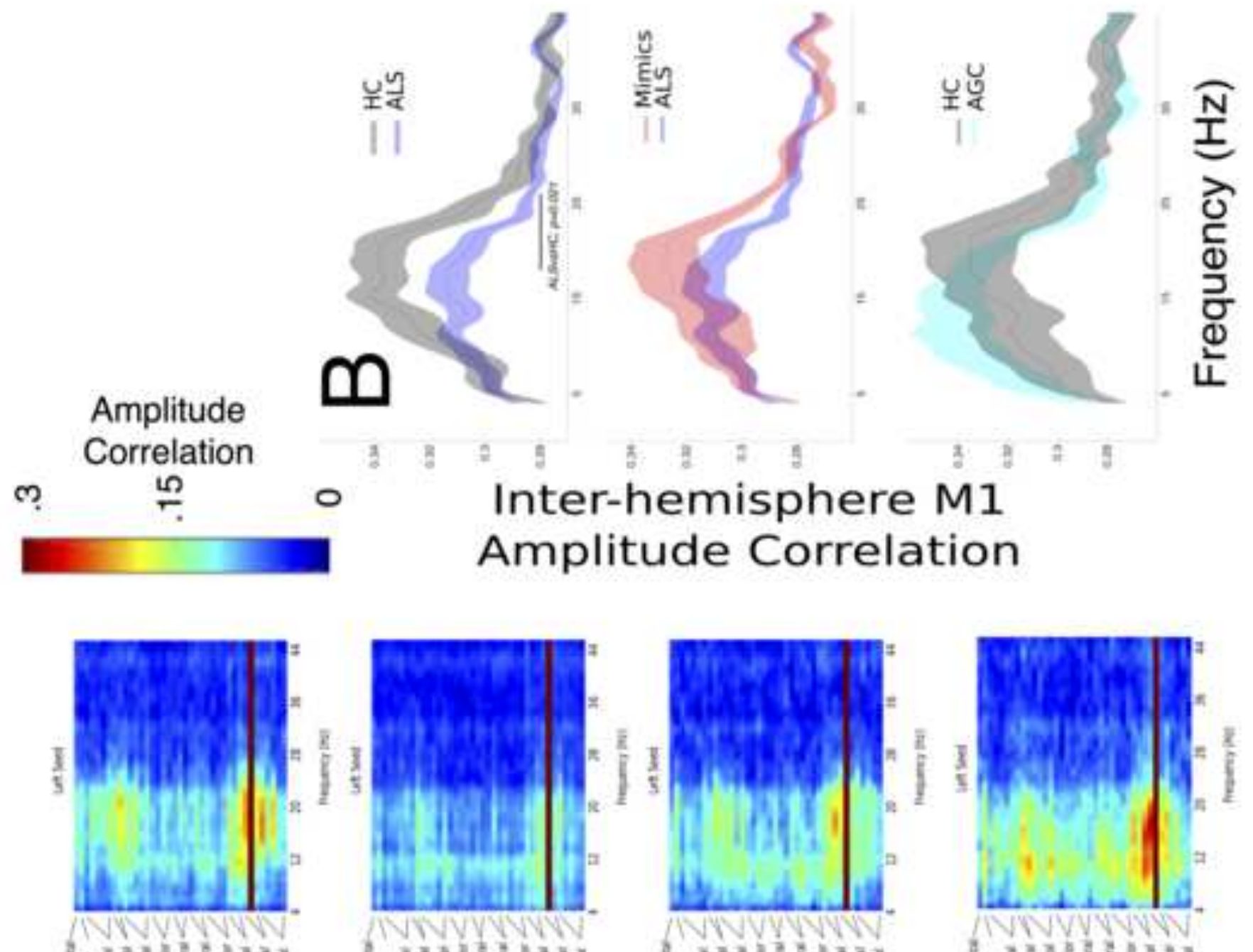

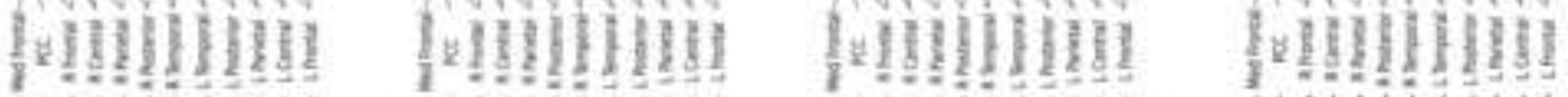

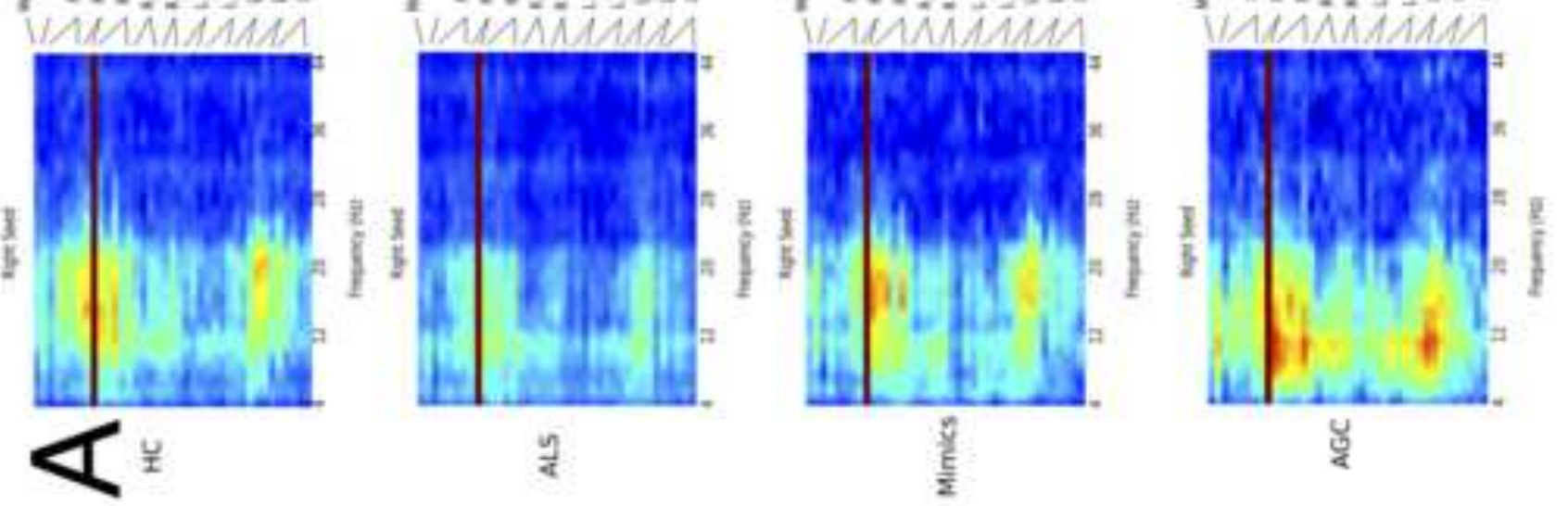

这 

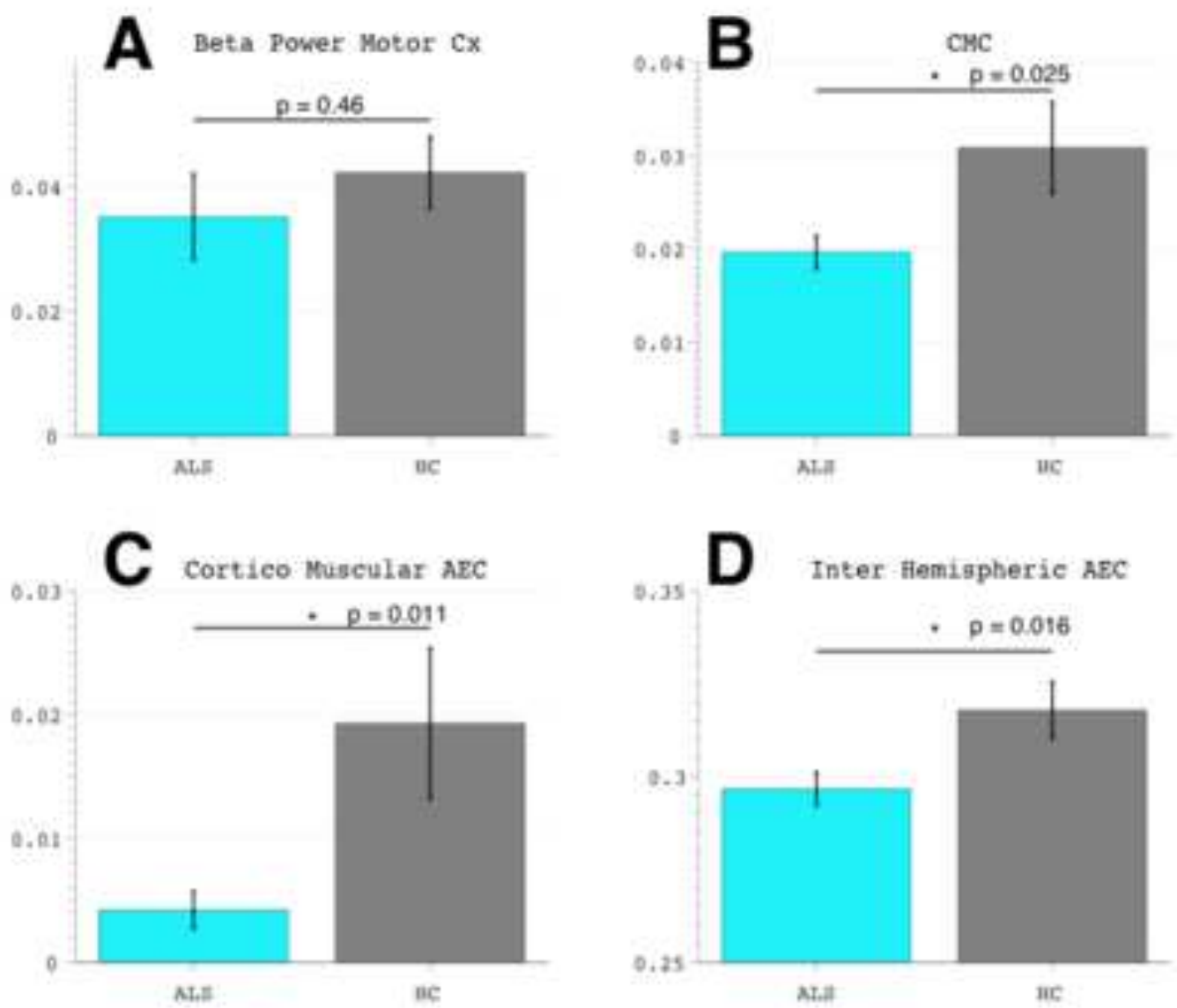


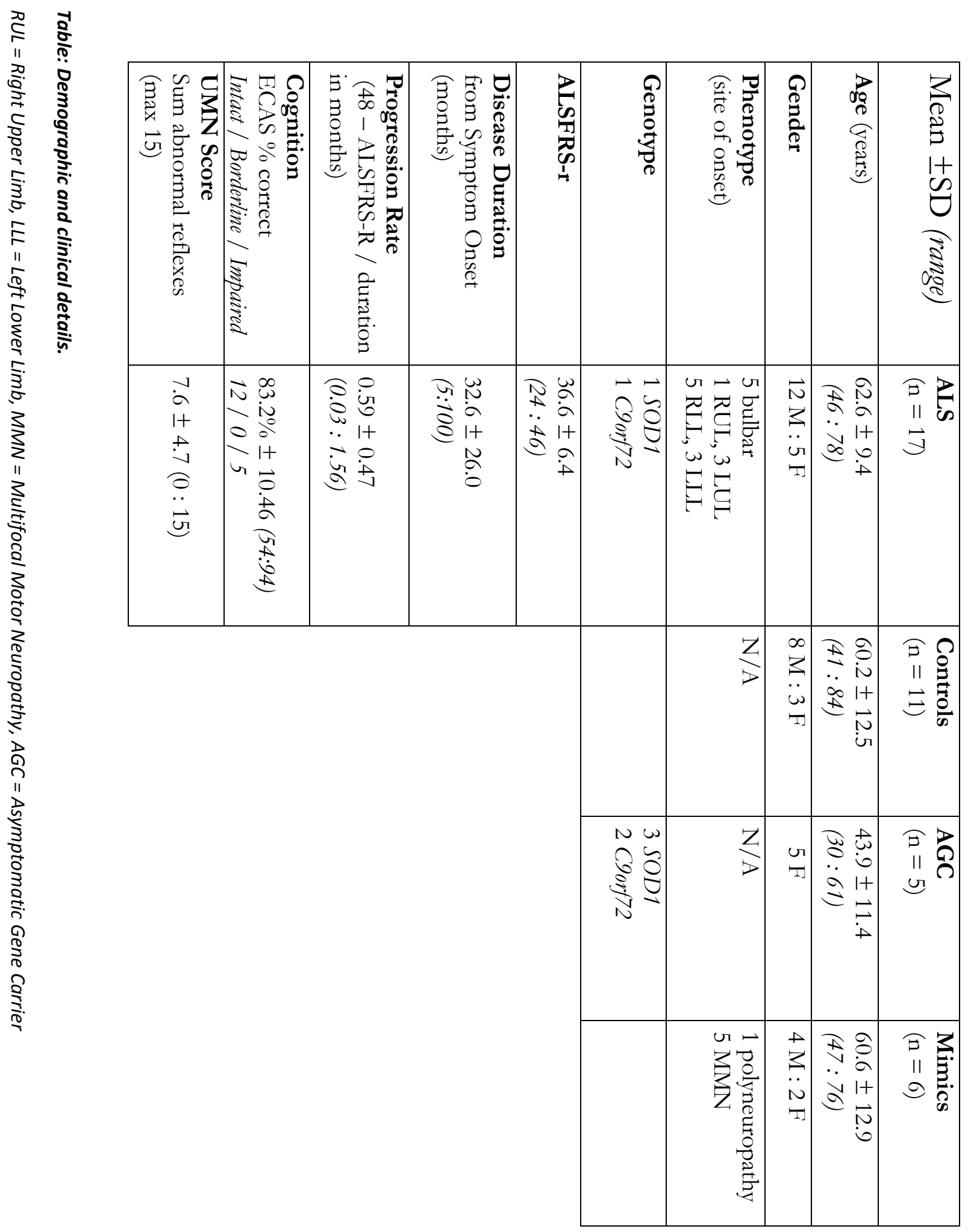

